\title{
A study on the relationship between Predictive HR Analytics and HRM practices in the IT sector
}

\author{
Shripria $\mathrm{V}^{1}$, Srividya $\mathrm{V}^{2}$ \\ \{sv.mba@psgtech.ac.in ${ }^{1}$, shripria@kctbs.ac.in $\left.{ }^{2}\right\}$ \\ ${ }^{1}$ Professor, KCT Business School, Kumaraguru College of Technology, ${ }^{2}$ Professor, PSG Institute of \\ Management, PSG College of Technology
}

\begin{abstract}
A study to understand the influence of Predictive Analytics (PHRA) in managing Human Resources (HRM) that focuses on Human Resource Practices like recruitment, selection and placement, performance management and planningfor succession was done in the IT sector at Coimbatore. The research design for this study is descriptive, astructured questionnaire was used for data collection however both primary and secondary data were collected. The data was obtained from 163 respondents in the IT sector that included both software and enabled services. The data was analyzed using Structured Equation Modelling (SEM) and Warp PLS to determine the importance of the association between Predictive Human resource analytics and the practices like recruitment, selection and placement, performance management and planning for succession. The results of the studies revealed that PHRA and the human resource practices show a substantial positive association. On the basis of the data analysed, it can be concluded that PHRA is a useful tool for improving HRM practices and systems. As a result, the study suggests that firms begin adopting PHRA into HRM practices and procedures.
\end{abstract}

Keywords: Predictive HR Analytics (PHRA), Human Resource Management practices, Structured Equation Modelling (SEM).

\section{Introduction}

Human Resources have always been the company's most valuable asset. Human resources are always at the heart of a company's success. HR analytics is critical for aligning the HR strategy with the overall company plan(Weena 2016). Organizations around the world are providing more emphasis to the analytics of human resource (HR), as the it is understood that data driven decision making and strategy in this profession is being held to a higher standard.(Xylia 2018). It is a powerful instrument that has the potential to offer positive value to the HR department's functions while also boosting the efficacy and efficiency of all linked areas through logical and quantifiable explanations (Opatha 2020). Recruitment, selection, placement, training and development, planning for succession, retention of employees, engagement of human resources, pay, remuneration with benefits are all the areas where analytics plays a role in human resources management.Mishra,2016).Predictive analytics analyses a pattern of the data and establishes an association to check and determine if the same pattern in thebehaviorof employees will repeat again in the future, this enables the HR managers in any firm in any sector to be better prepared to deal with similar issues that arises in the future (Dr. Reena Mahapatr Lenka, 2020). This analysis involves evaluation and 
comprehension of the reasonfor such behaviour. This enables issuing alerts about the next best move, and interpreting the best and worst outcomes are based on the analyzed data. (Jabir et al. 2019). It serves as a tool for making decisions. HR analytics has a number of advantages, one of which is that it is an evidence-based study that assists HR professionals in making rational decisions while improving HR's strategic effect on business success (Singh, 2017). As a result, HR analytics has progressed from a tactical partner to a strategic centre of excellence. (Malla, 2018). Everything is data driven in today's modern world and predictive analytics helps a lot.

HR managers can use predictive analytics to solve a variety of problems by analyzing massive amounts of data and projecting problems that the company may experience in the future. It may also forecast human behavior and provide a practical answer in the areas of acquisition of talent, employee emotions, engagement of employees, planning for career, performance management and retention of employees. The managers use the enormous amount of data accessible to make the appropriate decisions for solving problems and to create better organizationsthat is a far better place to work.

By using predictive analytics on a vast quantity of data, HR can transform into a strategic partner, with data-driven, evidence-based forecasts assisting in making decisions ahead of time rather than relying on gut sense.

\section{Research Objective}

The research's goal is to find answers to the following questions:

1. To gain a better understanding of the association between the predictive analytics of human resources (PHRA) and practices if Human resources (HRM).

2. To determine whether Predictive HR Analytics (PHRA) improves the outcome of recruitment $\&$ selection outcomes.

3. To determine whether Predictive HR Analytics (PHRA) significantly improves the performance of employees and improves retention of employees.

4. To determine whether Predictive HR Analytics (PHRA) improves training and development.

5. To determine if Predictive HR Analytics (PHRA) can help with planning for succession.

The following five hypotheses are tested in this study:

H1: Predictive HR analytics (PHRA) have a positive relationship and significantly enhances the outcome of recruitment and selection process.

H2: Predictive HR analytics (PHRA) have a positive relationship and significantly enhances the process of managing the performance of employees.

H3: Predictive HR analytics (PHRA) have a positive relationship and significantly enhance the outcome of retention of employees.

H4: Predictive HR analytics (PHRA) have a positive relationship and significantly enhances training \& development outcomes.

H5: Predictive HR analytics (PHRA) have a positive relationship and significantly enhance succession planning. 


\section{Literature Review}

\section{Predictive HRAnalytics}

Dr. Reena (Mahapatra) Lenka (2020) demonstrates that the predictive analytics is a very effective tool that Human resource managers could use it to solve most of the organization's employee-related problems, such as acquisition of talent, employee motivationand performance management, engagement of employees, development of career and retention.Henry (2018) explained to practitioners and companies the value of a higher degree of HR analytics. Predictive analytics of human resources enables businesses to reduce expenses related to HR while improving business and the HR outcomes. Predictive HR Analytics is a technology that continuously evolves and expandsin its application that has the ability to achieve $100 \%$ accuracy in HR decision making that helps firms strategically. According to Malisetty, Sainath; Archana, R. V.; Kumari, K. Vasanthi (2017), predictive analytics can assist HR pioneers in examining the difficulties that arise naturally in HR practises. Xylia Kathleen M. Lydgate (2018) in their work analysed HR analytics, the strategic human resource practices, and the influence on the corporate performance in depth. According to Sujeet N. Mishra, Dev Raghvendra Lama, and Yogesh Pa (2016), industries will not be able to survive in the long term unless they have predictive analytics skills from human resource management. HRPA assists firms in reducing HR-related expenditures while improving company performance and employee satisfaction. According to Dr. P. Raghunadha Reddy and P. Lakshmikeerthi (2017), this evidence-based approach in business is undoubtedly paving the way for HR Analytics. HR Analytics is enabling firms to collect and analyze adequate quality data for explaining return on investments in HR, as well as driving best HR decisions with precise proof. HR analytics, according to Masese Omete H.H.D.P.J. Opatha (2020), is a datadriven analytical framework that focusses on solving the workforce problems by analyzing the data with a combination of software's and the application of statistical models and methodologies. This approach derives new insights for better decision making enabling enterprise leaders to optimizemanaging of human resourcesin increasing the strategic value of Human resources. According to Paul Ogunyomia and Nealia S. Bruningb (2016), there seems to be both direct and indirect impact of HR systems that improves human capital on the basis of performance outcomes.Debaprasad Chattopadhyay, Debanjana Deb Biswas Mukherjee, Saswati (2017) imply that the landscape for leveraging data and information has shifted substantially, and that successful firms are embracing advanced HR analytics approaches to generate strategic capabilities and competitive advantage.

\section{HRM Practices}

HR analytics, according to Dr. Anshu Lochab, Sunil Kumar, and Himanshi Tomar (2018), is a technique for improving the performance of decision-making connected to people in the organization. This research was conducted to better understand HR analytics and whether they have any bearing on an organization's performance. HR Analytics, according to Srinivasa Rao (2016), assists human resources in predicting employee attrition in advance and offers reasonable time to discover alternate resources or recruit new employees in order to avoid project execution issues. As a result, a robust process of selection and placement should be based on the metrics and analytics to make it be more effective. Khan et al., 2010.

Performance evaluation and organizational performance have been shown to have strong and 
favorable correlations in previous studies on performance management (Chang \& Chen, 2002; Ahmed \& Schroeders, 2003; Kuo, 2004; Hanley, 2005). Collins (2013) found that, in order to avoid a big turnover disaster, Black Hills Corporation used predictive analytics to figure exactly the number of employees will retire from service each year, the nature and qualification of people required to replace them, and the sources of new hiring. Some proactive companies, according to Nair (2014), have used analytics and implemented the efforts to use data to analyzethe productivity of employees that improves hiring and retention. Over 55\% of the firms in India believe that predictive analysis helps in selecting and hiring quality human resources. (Press Trust of India, 2015).

\section{Research Gap}

It is imperative that industries will not be able to have a competitive advantage if they do not apply predictive analytics skills in management of human resources. Predictive human resource analytics has a wide application and it is crucialto employ this in all aspects of managing human resources (Mishra 2016). However, using of the primary data acquired from respondents, this study attempts to understand the relationship between predictive human resource analytics and its impactin improving the results of human resource practices.A study to understand the influence of Predictive Analytics in managing Human Resources that focuses on Human Resource Practices like recruitment, selection and placement, performance management and planning for succession was done in the IT sector at Coimbatore.

\section{Research Medhodology}

The study is restricted to IT employees in Coimbatore. Data is collected using a structured questionnaire with 5 sections, Section 1 consists of demographic data of the respondents. In section 2, three questions related to recruitment and selection were used. The section 3 consists of questions about the performance management. Section 4 comprises of questions regarding retention. The section 5 has questions to know about training and development. The section 5 and section 6 consists of questions about the succession planning and concepts related to predictive HR analytics. This is a descriptive research project. The research is based on firsthand information. Primary data was acquired from 163 respondents via a questionnaire that was distributed to them via floating online forms. The main respondents of this study are employees working in IT services in Coimbatore as it is a general survey. The questionnaire was sent to the 200 respondents out of which 176 responses were received back. After checking and processing, a final of 163 responses were employed for analysis. Structural Equation Modeling (SEM) usually employed for performing casual modeling is used for analysis. SEM is a method of analyzing the structural link between measurable variables and latent constructs that combines multiple regression and component analysis. The steps involved in SEM method are model specification, identification, estimation, evaluation and modification (Hoyle, 1995; Kaplan, 2005). WarpPLS is a software which has graphical user interface for factor-based and variance based SEM analysis using the factor-based methods and partial least squares. This software has been used to apply the SEM. 


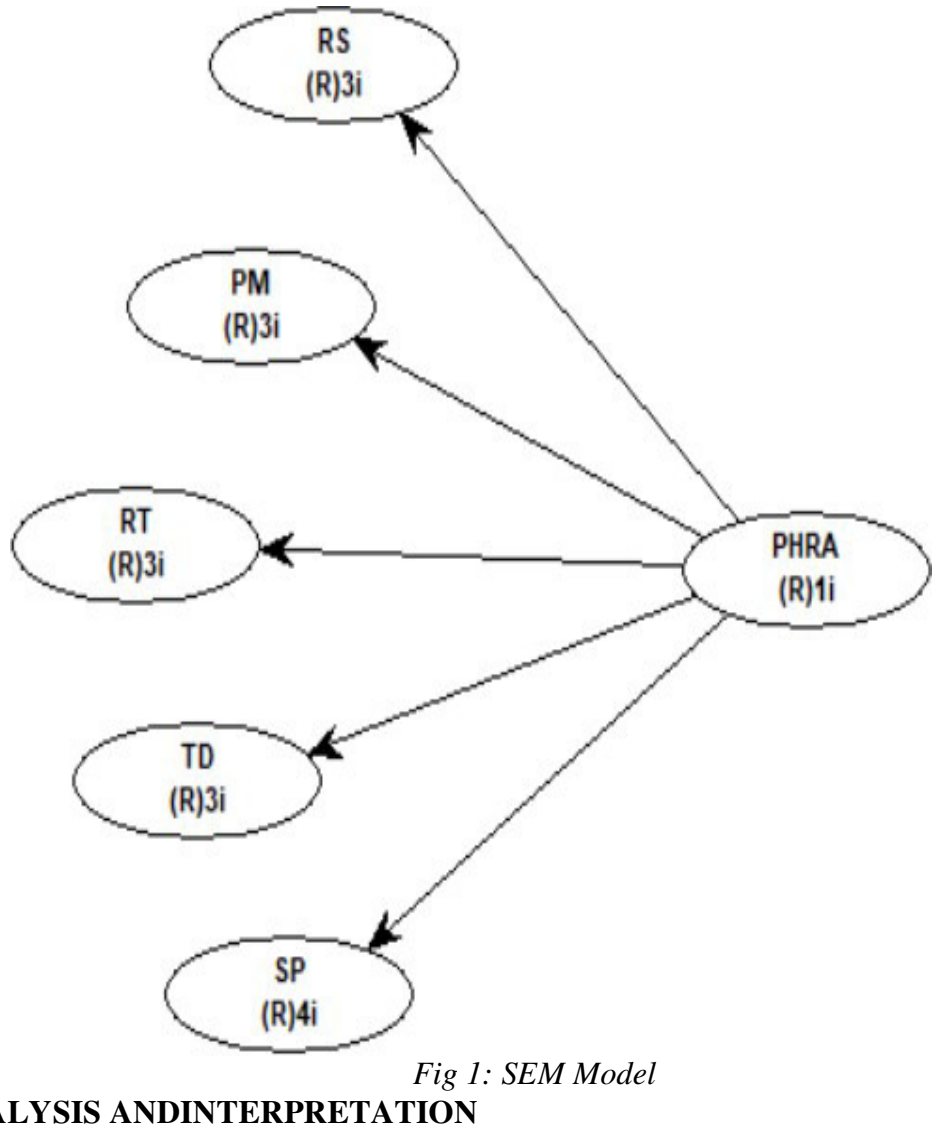

ANALYSIS ANDINTERPRETATION

\begin{tabular}{|l|l|l|}
\hline Particulars & Frequency & Percentage \\
\hline Gender & \multicolumn{2}{|l|}{} \\
\hline Male & 88 & 33.6 \\
\hline Female & 75 & 28.6 \\
\hline Monthly Income & & 1.5 \\
\hline Upto 20,000 & 4 & 28.6 \\
\hline Upto 40,000 & 75 & 17.6 \\
\hline Upto 60,000 & 46 & 6.5 \\
\hline Upto $1,00,000$ & 17 & 0.8 \\
\hline Above $1,00,000$ & 2 & \\
\hline
\end{tabular}

From the above table, we can interpret that the female respondents are more in number than the male respondents. Majority of employees were having a monthly income upto Rs. 40,000 accounting for $28.6 \%$ ( 75 out of 163 respondents), followed by employees earning income upto Rs. 20,000 which accounts for $17.6 \%$ (46 out of 163) and 17 out of 163 
respondents earn income up to Rs. $1,00,000$ (6.5\%). This is followed by respondents earning salary up to Rs. 20,000 (4 out of 163) which accounts for $1.5 \%$ and finally 2 respondents earn more than Rs. 1,00,000 (0.8\%).

\section{Results}

SEM analysis is used to investigate the relationship between HRM practices (variables include recruiting and selection, performance management, retention, training and development, and succession planning) and Predictive HR Analytics. However, using primary data acquired from respondents, this study focusses to analyze the relationship between predictive human resourceanalytics and its effect on improving the results of HRM practices. According to the findings, there is a strong positive correlation between recruiting and selection and Predictive HR Analytics (beta $=0.24 ; \mathrm{p}<0.01$ ); retention and predictive HR Analytics (beta $=0.25$ and $\mathrm{p}<0.01$ ); training \& development and predictive HR Analytics (beta $=0.23$ and $\mathrm{p}<0.01$ ); succession planning and predictive HR Analytics (beta=0.30 and $\mathrm{p}<0.01$ ) and insignificant relationship between performance management and predictive HR Analytics (beta $=0.17$ and $\mathrm{p}<0.01$ ).

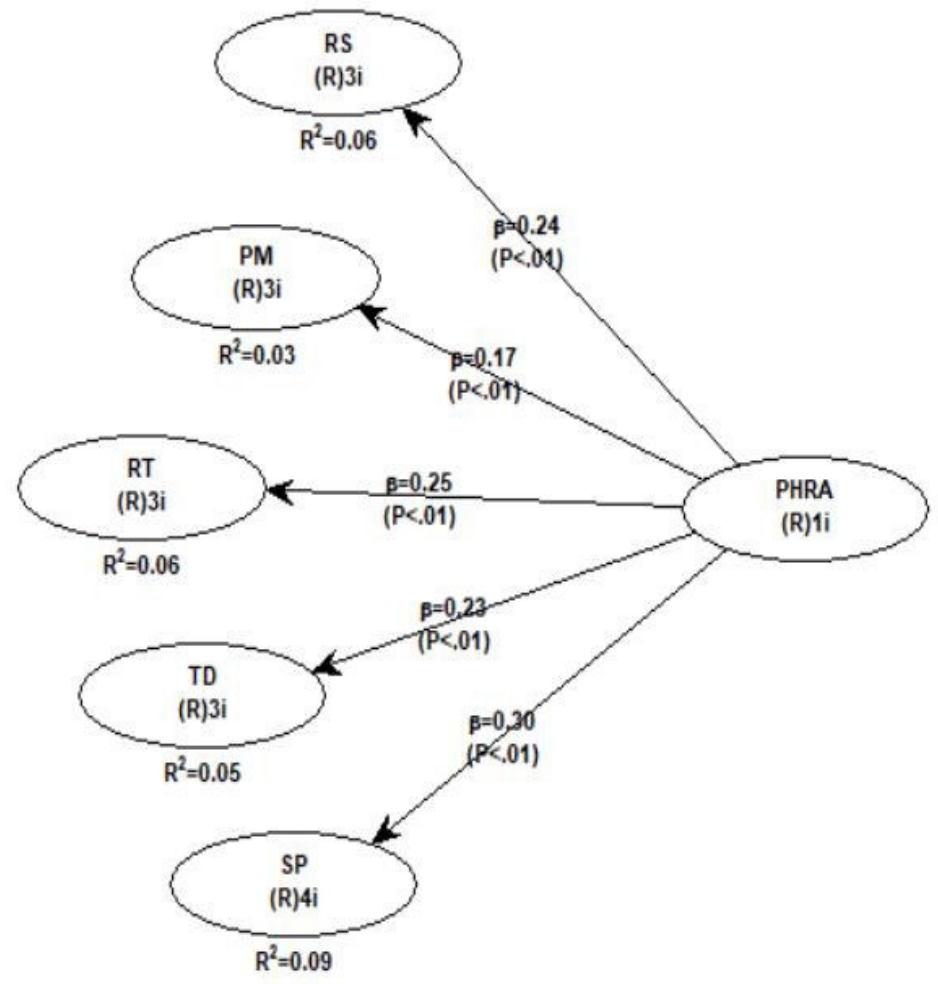

Fig 2: Results of Structured Equation Modeling 


\section{FINDINGS}

H1: Predictive HR Analytics (PHRA) has a positive relationship and significantly enhances the outcome of recruitment and selection process.

The path coefficients of hypothesis 1 are 0.24 , implying that for every $100 \%$ increase in the use of predictive HR analytics, there is a $24 \%$ rise in recruitment and selection outcome. The $\mathrm{p}$ value of the regression used to test $\mathrm{H} 1$ is 0.000 , which is less than 0.05 , that indicates that the relationship is quite significant.This supports the previous study of (Henry Ejio Orusa, 2018 - The study was able to demonstrate that PHRA and human resource practices of (recruitment, selection, management of performance and succession planning) has association that is significant and strong. H2: Predictive HR Analytics (PHRA) has a positive relationship and significantly enhances the process of managing the performance of employees.

The path coefficient in Hypothesis 3 is 0.17 , which suggests that for every $100 \%$ increase in the use of predictive HR analytics, the performance management outcome increases by $17 \%$. The $\mathrm{p}$ value of the regression used to test $\mathrm{H} 2$ is 0.000 , which is less than 0.05 , indicating that the association is significant.This supports the previous study of (Henry Ejio - Orusa, 2018 - The study was able to demonstrate that PHRA and HR practices has a strong and substantial association.

H3: Predictive HR Analytics (PHRA) has a positive relationship and significantly enhances retention of employees.

Hypothesis 3 also has a path coefficient of 0.25 , which suggests that for every 100 percent increase in the use of predictive HR analytics, the retention rate increases by $25 \%$. The $\mathrm{p}$ value of the regression used to test $\mathrm{H} 3$ is 0.000 , which is less than 0.05 , indicating that the link is significant.

H4: Predictive HR Analytics (PHRA) has a positive relationship and significantly enhances training $\&$ development outcomes.

Hypothesis 4 also has a path coefficient of 0.23 , indicating that for every $100 \%$ increase in the use of predictive HR analytics, there is a $23 \%$ rise in training and development. The $p$ value of the regression used to test $\mathrm{H} 1$ is 0.000 , which is less than 0.05 , indicating that the link is significant.

H5: Predictive HR Analytics (PHRA) has a positive relationship and significantly enhancessuccession planning.

Hypothesis 5 also has a path coefficient of 0.30 , indicating a $30 \%$ increase in succession planning outcomes for every $100 \%$ increase in the use of predictive HR analytics. The p value for the regression utilized for testing is 0.000 , which is less than 0.05 , indicating that the link is significant. This supports the previous study of (Henry Ejio - Orusa, 2018 - The study was able to demonstrate that PHRA and HR practices has a strong and substantial association.

As a result of the hypotheses, the study's five (5) research questions were addressed and answered as follows:

1. Predictive HR Analytics (PHRA) has a positive relationship and significantly enhances the outcome of recruitment, selection and placement process.

2. Predictive HR Analytics (PHRA) has a positive relationship and significantly enhances the process of managing performance of the employees.

3. Predictive HR Analytics (PHRA) has a positive relationship and significantly enhances retention of employees.

4. Predictive HR Analytics (PHRA) has a positive relationship and significantly enhancestraining and development outcomes. 
5. Predictive HR Analytics (PHRA) has a positive relationship and significantly enhances the planning of succession to be effective.

\section{CONCLUSION}

The study on predictive human resource analytics and human resource practices like as recruitment process with selection and placement, employee performance management, employee retention and engagement with training and development and planningfor succession has a strong significant association. The study finds that PHRA is such an excellent tool that it helps to handle most of the organization's challenges in terms of recruiting \& selection, performance management, retention, training \& development, and succession planning, in support with (Henry, 2016). It can be used to anticipate which employees are planning to leave the company or who are looking for a new employment. PHRA is also a useful technique for selecting successors withoutbias. PHRA assists firms in managing employee performance and controlling HR-related costs. As a result, PHRA is a necessity of the hour because it is a highly effective instrument for cost management and making objective decisions. It also backs up (Henry, 2016)'s conclusion that PHRA is a continuously evolving and expanding

\section{SCOPE FOR FUTURESTUDY}

The association of predictive human resource analytics and human resource practices like as recruitment, selection and placement, employee performance management, employee retention and engagement with training and development, and planning for succession is discussed in this study. The study can be utilized to solve employee-related difficulties in the future, and this paper does not address motivation, performance management, employee engagement, career development, or emotional intelligence. Emotional intelligence and employee engagement are two major subjects that could be addressed in future research.

\section{SUGGESTIONS}

From the study it is established that here is a strong link between Predictive human resource analytics (PHRA) and Human resource practices.It is imperative that organizations that are proactive and ahead of the learning curve would look into ways and means of incorporating PHRA into these HRM practices. The organizations should earmark budgets for investments into the technologies required and means to implement the same to enable large data collection, retention and analysis. The results of the predictive analysis need to be made available in the hands of the decision makers at the right time in the right format in order to aid in decision making. This practice would definitely have a strategic impact on the organizational performance and enable companies to have a competitive advantage. 


\section{References}

[1] Bruningb, P. O. (2016). Human resource management and organizational performance of small and medium enterprises (SMEs) inNigeria.

[2] Dr. Anshu Lochab, S. K. (2018). Impact of Human Resource Analytics on Organizational Performance: A Review of Literature UsingR-Software.

[3] Dr. P. Raghunadha Reddy, P. L. (2017). 'HR Analytics' - An Effective Evidence Based HRMTool.

[4] Emanoil Muscalu, A. S. (2014). HR Analytics for strategic Human Resource Management. Management challenges for sustainabledevelopment.

[5] Kamel Barbar1, R. C. (2019). The Impact of HR Analytics on the Training and Development Strategy - Private Sector Case Study in Lebanon. Journal of Management andStrategy.

[6] Lenka, D. R. (2020). Predictive Analytics - A Game Changer in HR. Journal of CriticalReviews.

[7] Lydgate, X. K. (2018). Human Resource Analytics: Implications for Strategy Realization and Organizational Performance.

[8] Malisetty, S., Archana, R. V., \& Kumari, K. V. (2017). Predictive Analytics in HR Management. Indian Journal of Public Health Research \&development.

[9] Masese Omete Fred, D. U. (2015). Overview of HR Analytics to maximize Human capitalinvestment.

[10] Mukherjee, D. C. (2017). A New Look at HRAnalytics.

[11] Opatha, H. (2020). HR Analytics: A Literature Review and New Conceptual Model. International Journal of Scientific and ResearchPublications.

[12] Orusa, H. E. (2018). Predictive HR Analytics and Human Resource Management. Global ScientificJournals.

[13] Rao, S. (n.d.). Turnover Analytics \& Forecasting Hiring Demand: HRDomain.

[14] Sujeet N. Mishra, D. R. (2016). Human Resource Predictive Analytics (HRPA) For HR Management In Organizations. International journal of scientific \& technologyresearch.

[15] Sujeet Narendra Mishra, D. R. (2016). A Decision Making Model for Human Resource Management in Organizations using Data Mining and PredictiveAnalytics. 